Gut, 1987, 28, 1600-1604

\title{
Psychiatric illness in patients with inflammatory bowel disease
}

\author{
H ANDREWS, P BARCZAK, AND R N ALLAN \\ From the Gastroenterology Unit, General Hospital, Birmingham
}

SUMmaRY One hundred and sixty two consecutive patients attending a clinic for inflammatory bowel disease (91 Crohn's, 71 ulcerative colitis) were assessed for the presence of anxiety and depression using a simple self-rating questionnaire (HAD scale) and a detailed evaluation (DSMIII). The overall prevalence of psychiatric illness (DSM-III) in ulcerative colitis and Crohn's disease was $34 \%$ and $33 \%$ respectively. There was no statistically significant association in ulcerative colitis patients between the presence of psychiatric illness and the present physical illness. Psychiatric illness was more common in the physically ill patients with Crohn's disease, compared with those who were well: $50 \% v 8 \%(\mathrm{p}<0.01)$, using (HAD) criteria $66 \% v 37 \%(\mathrm{p}<0.001)$. The presence of patients between the presence of psychiatric illness and the presence of physical illness. Psychiatric who were well: $50 \% \vee 8 \%(\mathrm{p}<0.01)$ by DSM-III criteria, using (HAD) criteria $66 \% \vee 37 \%$ $(\mathrm{p}<0 \cdot 001)$. The presence of psychiatric illness adversely affected physical recovery. Seventeen per cent recovered when psychiatrically ill $v 53 \%$ when psychiatrically well $(\mathrm{p}<0 \cdot 025)$. The HAD scale was assessed as a screening method for psychiatric illness in this medical setting and had a sensitivity of $76 \%$ and a specificity of $79 \%$.

There have been few previous studies investigating the interaction between physical and psychiatric illness in patients with inflammatory bowel disease (IBD). A recent mortality survey of Crohn's disease' found an excess of suicides in women and a review of our own case records revealed that nearly $25 \%$ of 779 patients had been treated at some time for a depressive illness.

Ulcerative colitis and Crohn's disease are chronic, potentially disabling conditions with symptoms of pain, diarrhoea and weight loss, often requiring surgical treatment, sometimes with stoma formation. The illness may disrupt work, family and social life and it is perhaps surprising that two recent studies from the USA ${ }^{23}$ failed to find an association for either Crohn's disease or ulcerative colitis between the presence of psychiatric illness and the degree of attendant physical morbidity. A growing awareness of the importance of psychological factors in the management of chronic illness stimulated the present study.

We have assessed the prevalence of anxiety and depression in IBD and have also tested a simple

Address for correspondence: Dr Robert Allan. The General Hospital. Steelhouse Lane, Birmingham B4 $6 \mathrm{NH}$.

Received for publication 8 May 1987. self-rating questionnaire, the Hospital Anxiety and Depression Scale (HAD) ${ }^{+}$as a screening method for detecting psychiatric illness.

\section{Methods}

PATIENTS

One hundred and sixty two consecutive patients (91

Crohn's disease, 71 ulcerative colitis) attending an IBD clinic were interviewed. An index of physical morbidity was obtained using a clinical rating scale administered by one of us (HA) (Table 1), and all patients completed the Hospital Anxiety and Depression (HAD) scale which is an easily administered self-rating questionnaire. It consists of 14 questions (seven relating to depression and seven to anxiety) which assess the symptoms of anxiety and depression in the previous week. The responses to the questions are not affected by the presence of physical illness. Patients scoring more than 8 (maximum 21) on either part of the test can be regarded as suffering from anxiety or a depressive disorder (Table 2).

A sample of 80 patients taken at random from this group were interviewed by a liaison psychiatrist (PJB) who was blind to the results of the HAD and 
Table 1 Clinical rating scale for assessment of physical well being in patients with IBD

\begin{tabular}{lll}
\hline & & Score \\
1 & General well-being & $0-3$ \\
2 & Abdominal pain & $0-3$ \\
3 & Diarrhoea/flux & $0-3$ \\
4 & Extra intestinal manifestations & $0-3$ \\
5 & Treatment & $0-3$ \\
Total Score $>5$ indicates physical illness. & \\
\hline
\end{tabular}

physical assessment. The structured clinical interview for DSM-III was used to obtain diagnosis according to DSM-III criteria.5 The DSM-III is a system for classifying psychiatric disorder developed in the USA based on clearly defined diagnostic criteria and is widely used throughout the world."

\section{Results}

PSYCHIATRIC DISORDER IN PATIENTS WITH IBD CROHN'S DISEASE

Details of sample population

Ninety one patients (63\% women) with Crohn's disease were examined. Their ages ranged from 14-83 years (mean age 43$)$. Fifteen patients $(17 \%)$ had a stoma before the study and the treatment in a further six included stoma formation during the follow up period.

Table 2 The HAD Scale questionnaire consists of seven questions concerned with anxiety and seven with depression. The patient ticks one of four boxes associated with each question which are scored from Normal $=0$ to Severely affected $=3$

\begin{tabular}{|c|c|}
\hline I feel tense and wound up & $\begin{array}{l}\text { I still enjoy the things I used to } \\
\text { enjoy }\end{array}$ \\
\hline $\begin{array}{l}\text { I get sort of frightened feeling } \\
\text { as if something awful is about } \\
\text { to happen }\end{array}$ & $\begin{array}{l}\text { I can laugh and see the funny } \\
\text { side of things }\end{array}$ \\
\hline $\begin{array}{l}\text { Worrying thoughts go through } \\
\text { my mind }\end{array}$ & I feel cheerful \\
\hline $\begin{array}{l}\text { I can sit at ease and feel } \\
\text { relaxed }\end{array}$ & I feel as if I am slowed down \\
\hline $\begin{array}{l}\text { I get a sort of frightened feeling } \\
\text { like 'butterflies' in my } \\
\text { stomach }\end{array}$ & $\begin{array}{l}\text { I have lost interest in my } \\
\text { appearance }\end{array}$ \\
\hline $\begin{array}{l}\text { I feel restless as if I have to be } \\
\text { on the move }\end{array}$ & $\begin{array}{l}\text { I look forward with enjoyment } \\
\text { to things }\end{array}$ \\
\hline I get sudden feelings of panic & $\begin{array}{l}\text { I can enjoy a good book or TV } \\
\text { programme }\end{array}$ \\
\hline
\end{tabular}

Table 3 Follow-up of psychiatric and physical illness without intervention

\begin{tabular}{|c|c|c|c|c|c|}
\hline \multicolumn{2}{|c|}{ Status at first evaluation } & \multicolumn{4}{|c|}{ Subsequent status at second evaluation } \\
\hline & & Well & $\begin{array}{c}\text { Physically } \\
\text { III }\end{array}$ & $\begin{array}{c}\text { Psychiatrically } \\
\text { III }\end{array}$ & Both \\
\hline \multicolumn{6}{|c|}{ Crohn's discase $(n=86)$} \\
\hline Well & 29 & 21 & 2 & 4 & 2 \\
\hline Physically ill & 17 & 9 & 5 & - & 3 \\
\hline Psychiatrically ill & 17 & 1 & 1 & 9 & 6 \\
\hline Both & 23 & 2 & - & 2 & 19 \\
\hline \multicolumn{6}{|c|}{ Ulcerative colitis ( $n=65)$} \\
\hline Well & 27 & 20) & 2 & 5 & - \\
\hline Physically ill & 12 & 6 & 4 & - & 2 \\
\hline Psychiatrically & 13 & 6 & - & 5 & 2 \\
\hline Both & 13 & 3 & 3 & 4 & 3 \\
\hline
\end{tabular}

Details of follow-up

Four patients were lost to follow up, one died, and the remaining 86 were re-interviewed (Table 3). During this period 13 physically ill patients got better (remission rate $32.5 \%$ ) and 11 physically healthy patients became ill (relapse rate $24 \%$ ). Nine patients $(20 \%)$ developed a psychiatric disorder and only four with an existing psychiatric disorder improved (remission rate $10 \%$ ). The presence of concurrent psychiatric illness appeared to influence physical recovery in that only four of $23(17 \%)$ recovered physically when a psychiatric disorder was present compared with nine of $17(53 \%)$ when there was no psychiatric disorder $(\mathrm{p}<0 \cdot()(0) 1)$

\section{Relationship between physical morbidity and} psychiatric illness

The prevalence of psychiatric disorder according to DSM III criteria (Table 4) was 33\%. The prevalence of psychiatric disorder was independent of the age and sex of a patient and also of the presence or absence of a stoma.

Table 4 Prevalence of psychiatric disorder (DSM-III) classification)

\begin{tabular}{lcl}
\hline & $\begin{array}{c}\text { Crohn's disease } \\
(n=45)\end{array}$ & $\begin{array}{c}U C \\
(n=35)\end{array}$ \\
\hline $\begin{array}{l}\text { Simple/social phobia } \\
\text { Generalised anxiety disorder } \\
(\mathrm{GAD})\end{array}$ & 3 & 3 \\
$\begin{array}{l}\text { Dysthymia/major depressive } \\
\text { disorder }\end{array}$ & 11 & 5 \\
$\begin{array}{l}\text { Total prevalence of } \\
\text { psychiatric disorder }\end{array}$ & $15(33 \%)$ & $12(34 \%)$ \\
\begin{tabular}{l} 
Prevalence of GAD/depression \\
\hline
\end{tabular} & $12(27 \%)$ & $9(26 \%)$ \\
\hline
\end{tabular}


Table 5 Positive cases of psychiatric illness on HAD and physical morbidity in IBD

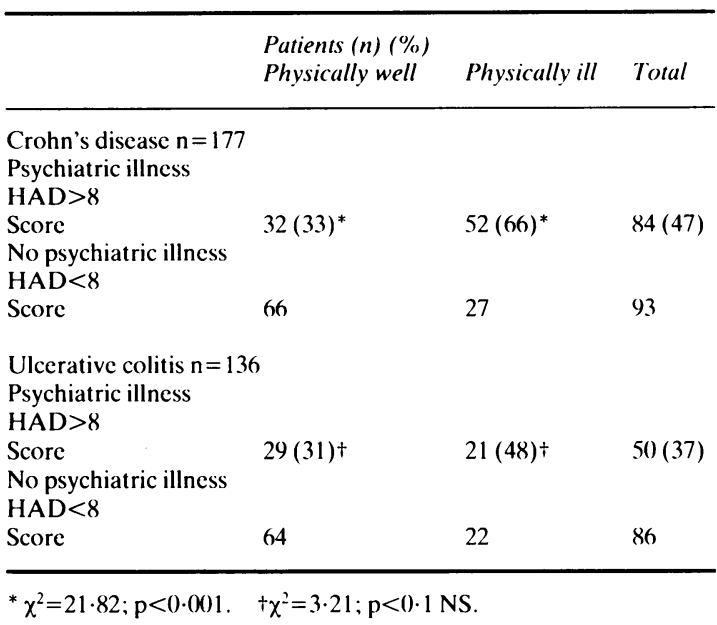

A total of 177 HAD tests were available for analysis including those patients who were interviewed twice. The patients were divided into four groups depending on the presence or absence of current physical and psychiatric illness. The findings are presented separately for the HAD and DSM-II diagnosis. Phobic disorders are not included in the analysis as they were usually of many years duration (Tables 5 and 6).

There is a statistically significant association between the presence of psychiatric illness and physical ill health. Sixty six per cent of the physically ill patients had a psychiatric illness on the HAD criteria compared with $37 \%$ in the physically well group. The overall prevalence of psychiatric disorder is much lower using the more stringent DSM-III criteria. The association is still present, however, with a prevalence in ill patients of $50 \%$ compared with $8 \%$ in the healthy.

Table 6 Psychiatric illness DSM-III and physical morbidity in IBD

\begin{tabular}{llll}
\hline & $\begin{array}{l}\text { Patients }(n)(\%) \\
\text { Physically well }\end{array}$ & Physically ill & Total \\
\hline Crohn's disease $\mathrm{n}=45$ & & $10(50)^{*}$ & $12(27)$ \\
$\begin{array}{l}\text { Psychiatric illness } \\
\text { No psychiatric illness }\end{array}$ & $23(8)^{*}$ & 10 & 33 \\
Ulccrative colitis $\mathrm{n}=35$ & & & \\
Psychiatric illness & $6(46)^{\dagger}$ & $3(14)^{\dagger}$ & $9(26)$ \\
No psychiatric illness & 7 & 19 & 26 \\
\hline
\end{tabular}

${ }^{*} \chi^{2}=7.99 ; \mathrm{p}<0 \cdot(0) 1 . \quad+\chi^{2}=2.98 ; \mathrm{p}<0.1 \mathrm{NS}$.
ULCERATIVE COLITIS

\section{Details of sample population}

Seventy one patients ( $54 \%$ women) with ulcerative colitis were examined. Their ages ranged from 12-77 years (mean age 48$)$. Twenty seven patients $(29 \%)$ had a stoma before the study started.

\section{Details of follow-up}

Four patients were lost to follow up, two died of ischaemic heart disease, and the remaining 65 were re-interviewed (Table 3). During this period 13 physically ill patients got better (remission rate $52 \%$ ) and four physically healthy patients became ill (relapse rate $10 \%)$. Seven patients $(18 \%)$ developed a psychiatric disorder and 12 with an existing psychiatric disorder improved (remission rate $46 \%$ ). The presence of concurrent psychiatric illness did not affect physical recovery.

\section{Relationship between physical morbidity and psychiatric illness}

The prevalence of psychiatric disorder according to DSM-III criteria (Table 4 ) was $34 \%$. The prevalence of psychiatric disorder was independent of the age and sex of the patient and also of the presence or absence of a stoma.

A total of 136 HAD tests were available for analysis. The patients were divided into four groups depending on the presence or absence of current physical and psychiatric illness. The findings are presented separately for the HAD and DSM-III (Tables 5 and 6). Phobic disorders have also been excluded from this analysis. In the group with ulcerative colitis unlike the findings in the Crohn's disease, there was no statistically significant association between physical and psychiatric morbidity.

SENSITIVITY AND SPECIFICITY OF THE HAD AS A SCREENING TEST FOR PSYCHIATRIC DISORDERS

The value of the HAD as a screening tool for psychiatric illness was also examined. The DSM-III diagnosis was used as the standard against which the performance of the HAD was evaluated.

The sensitivity has been expressed as a ratio of the cases identified by HAD and all the cases of psychiatric illness diagnosed on DSM-III. The specificity is the ratio of true negatives identified by HAD to all the true negatives on DSM-III.

Using a cutoff score of $8+$ for either anxiety or depression, the sensitivity of the HAD was $76 \%$ $(16 / 21)$ and the specificity $79 \%(47 / 59)$.

\section{Discussion}

A review of the psychological and social outcomes of Crohn's disease ${ }^{7}$ has highlighted the lack of methodo- 
logically sound data. Three studies ${ }^{\mathrm{x}-11}$ which fulfil many of the necessary criteria such as the use of a standardised psychiatric interview and randomly selected patients, found a prevalence of psychiatric disorders of between $30-35 \%$. A recent careful assessment of physical and psychiatric morbidity among 50 consecutive referrals to a gastroenterology clinic has been carried out and compared with a control group of 50 chronically ill medical outpatients. ${ }^{3}$ The prevalence of psychiatric disorder was higher in the Crohn's disease group compared with the control group $(52 \% v 30 \%)$ thus confirming Crohn's original finding." There was however, no association between the degree of physical morbidity and the presence of psychiatric disorders.

The same workers, ${ }^{2}$ discounting several previous studies where diagnostic methods were imprecise and sample sizes small ${ }^{12-16}$ adopted a similar research strategy in seeking an association between physical morbidity and psychiatric illness in ulcerative colitis. The prevalence of psychiatric illness was similar in the ulcerative colitis group compared with the controls $(26 \% v 30 \%)$ and once again no association was shown between psychiatric illness and physical morbidity.

In the present study for patients with ulcerative colitis there was no significant association between physical morbidity and psychiatric illness, confirming Heltzer's previous finding.'

For Crohn's disease, in contrast with Heltzer's finding there was a clear association between the presence of psychiatric illness and the degree of physical morbidity using both HAD and more stringent DSM-III criteria. It may be that the different methods for assessment of physical morbidity and psychiatric disorders influenced the results. The method adopted in this study sought an association at one 'point in time' whereas Heltzer evaluated psychiatric illness and physical morbidity over time. The methods used in the present study are probably more effective in diseases where spontaneous relapses and remission are common.

The usefulness of the HAD as both a rating and screening tool has been established in recent studies. The HAD compares favourably with the General Health Questionnaire GHQ as a screening tool for psychiatric disorders. ${ }^{17}$ As a rating scale it has been compared favourably against the Montgomery Asberg Depression Rating Scale, Beck Depression Inventory, and the Clinical Anxiety Scale. ${ }^{1 \times 19}$

In the present study the HAD performed well when compared with DSM-III diagnosis as a screening method of identifying anxiety or depression in the inflammatory bowel disease clinic and the sensitivity and specificity were similar to previous findings. ${ }^{+}$It should be emphasised that the HAD scale is not a general screening tool for all psychiatric disorders, but a rating scale for anxiety and depression only.

Patients with psychiatric illness in the hospital and general practice setting will respond to treatment despite the presence of physical illness. ${ }^{21.24} \mathrm{~A}$ recent survey of Oxford Hospitals"s however, found that one third of physicians and four fifths of surgeons, never used antidepressants. Most of the patients with psychiatric illness identified in this study could have been managed by their general practitioner or hospital doctor. The remission rate for untreated psychiatric disorders was low $(10 \%)$ for both ulcerative colitis and Crohn's disease. The HAD scale is both easy to administer and interpret by non-psychiatric staff. Its regular use could detect previously unrecognised psychiatric disorders in patients with IBD which would respond readily to treatment.

\section{References}

1 Prior P, Gyde S, Cooke WT, Waterhouse JAH, Allan RN. Mortality in Crohn's disease. Gastroenterology 1981; 80: 307-12.

2 Heltzer JE, Stillings WA, Chammas S, Norland CC, Alders DH. A controlled study of the Association between U.C. and psychiatric diagnoses. Dig Dis Sci 1982; 27: 513-18.

3 Heltzer JE, Chammas S, Norland CC, Stillings WA, Alpers DH. A study of the Association between Crohn's disease and psychiatric illness. Gastroenterology 1984; 86: $324-30$.

4 Zigmond AS, Snaith RP. The Hospital Anxiety and Depression Scale. Acta Psychiatr Scand 1983; 67: 361-70.

5 Spitzer RL. Structured clinical interview for DSM III. New York: New York State Institute, 1983.

6 American Psychiatric Association Committee on Nomenclature and Statistics. Diagnostic and statistical manual of mental disorders. 3 ed (DSM III) Washington DC: American Psychiatric Association, 1980.

7 Latimer PR. Crohn's disease: A review of the psychological and social outcome. Psychol Med 1978; 8: 649-56.

8 McKegney FP, Gordon RD, Levine SM. A psychosomatic comparison of patients with UC and Crohn's disease. Psychosom Med 1970; 32: 153-66.

9 Ford CV, Golder GA, Castelnuovo-Tedesco P. A psychiatric study of patients with regional enteritis. JAMA 1969; 208: 311-5.

10 Sheffield BG, Carney MWP. Crohn's disease: A psychosomatic illness. BrJ Psychiatry 1976; 128: 446-50.

11 Crohn BB. Regional ileitis. New York: Grune \& Stratton, 1949.

12 Sloan WP, Bargen JA, Gage RB. Life histories of patients with chronic ulcerative colitis: A review of 2000 cases. Gastroenterology 1968; 54: suppl 819-22.

13 Mendeloff AI, Monk M, Lilienfield SC. Illness experience and life stresses in patients with irritable colon and with ulcerative colitis. N Engl J Med 1970; 282: $14-17$. 
14 Esler MD, Goulston KJ. Levels of anxiety in colonic disorders. N Engl J Med 1973; 288: 16-20.

15 Feldman F, Cantor D, Soll S, Bachrach W. Psychiatric study of a consecutive series of 34 patients with ulcerative colitis. Br Med J 1967; 3: 14-17.

16 Fava GI, Pavan L. Large bowel disorders. II Psychopathology and alocithymia. Psycho Psychosom 1976; 27: $100-5$.

17 Goldberg D, Bridges K. Screening for psychiatric illness in General Practice: The general practitioners versus the screening questionnaire. J $R$ Coll Gen Pract 1987; 37: 15-18.

18 Snaith PR, Taylor CM. Rating scales for depression and anxiety; a current perspective. Br J Clin Pharmacol 1985; 19: 175-205.

19 Aylard PR, Gooding JH, McKenna PJ, Snaith RP. A validation study of three anxiety and depression selfassessment scales. J Psychosom Res 1987; 31: 261-8.
20 Anonymous. Treatment of depression in medical patients [Editorial]. Lancet 1986; i: 949-50.

21 Maguire GP, Hopwood P, Howell TN. Diagnosis of depression in cancer patients. Acta Psychiatr Scand $1985 ; 72 ; 81-2$.

22 Costa D, Mocos I, Toma T. Efficacy and safety of Mianserin in the diagnosis of depression in women with cancer. Acta Psychiatr Scand 1985; 72: suppl. 320: 8592.

23 Lipsey J, Robinson R, Pearlson G, Rao U, Price T. Nortriptyline diagnosis of post stroke depression: A double blind study. Lancet 1984; i: 297-9.

24 Zung W, Magill M, Moore J, George D. Recognition and diagnosis of depression in family practice. J Clin Psychiatry 1983; 44: 3-6.

25 Mayou R, Smith E. Hospital doctor's management of psychological problems. Br J Psychiatry 1986; 148: 194-7. 